\title{
Wanted and Unwanted Fertility in Bolivia: Does Ethnicity Matter?
}

\section{By Catherine B. McNamee}

Catherine B. McNamee is a doctoral candidate, University of Texas at Austin, Austin, TX, USA.

\begin{abstract}
CONTEXT: In Bolivia, the total fertility rate (TFR) among indigenous populations is higher than that among the nonindigenous population. It is important to investigate whether this difference is attributable to ethnic differences in wanted or unwanted fertility.
\end{abstract}

METHODS: Data from the 2003 Bolivian Demographic and Health Survey were used to estimate women's wanted and unwanted TFRs. Logistic regression analyses were conducted to examine whether women's, men's and couples'characteristics were associated with use of any contraceptive method and modern methods.

RESULTS: The TFRs for indigenous and nonindigenous women were 4.3 and 3.1, respectively. The wanted fertility rate for indigenous women was nearly the same as that for nonindigenous women (1.5 and 1.7, respectively); virtually all of the ethnic difference in the TFRs was attributable to the ethnic difference in unwanted fertility. The proportion of women in need of contraception was greater among indigenous women than among nonindigenous women (26\% vs. 19\%). In logistic regression analyses, male fertility preferences explained only a small part of the ethnic difference in contraceptive use.

CONCLUSION: Women's, men's and couples'preferences contribute only marginally to unwanted fertility, suggesting that structural factors act as obstacles to preventing unwanted fertility. International Perspectives on Sexual and Reproductive Health, 2009, 35(4):166-175.

The indigenous populations of Bolivia have continually exhibited a higher total fertility rate (TFR) than the nonindigenous population: For example, the overall TFR for indigenous groups was 6.9 in 1978 and 5.0 in 2001, compared with 6.0 and 3.6, respectively, for the nonindigenous population. ${ }^{1}$ The relatively high fertility of the country's indigenous populations may arise from higher fertility preferences, higher levels of unwanted fertility or both. Higher fertility preferences may reflect a need for more children to work in the home and on the family's land. Unwanted fertility may result from unmet need for contraceptives.

Previous studies, using indirect methods, did not disaggregate fertility into wanted and unwanted categories by ethnicity. ${ }^{2-7}$ This study examines whether indigenous women have higher fertility because they desire larger families or because they have more unwanted births, perhaps due to men's fertility preferences or men's influence on their partner's contraceptive use. How are women's, men's and couples' fertility preferences related to fertility outcomes? What potential discrepancies exist between preferred and actual fertility that might account for ethnic fertility differentials in Bolivia?

\section{BACKGROUND}

The definition of "indigenous" in Bolivia varies, complicating estimates; however, according to most studies more than half of the population of Bolivia is indigenous. ${ }^{* 8}$
Since the colonial period, the indigenous peoples of Bolivia have been economically, politically and socially marginalized. They have, however, maintained strong cultural identities, at least in part because they have been driven to more remote and underdeveloped areas of the country. ${ }^{9}$ In recent decades, political activism has dramatically increased the influence of the indigenous populations, leading to reforms in multilingual education and constitutional rights, as well as to the 2005 election of Evo Morales, the first indigenous president. ${ }^{10}$ Nevertheless, substantial inequality between indigenous and nonindigenous populations remains in income, education and access to health services. ${ }^{11}$

The disproportionate levels of poverty for indigenous populations relates to their concentration in rural areas, which tend to be poorer. ${ }^{6}$ However, even in urban areas, indigenous people are poorer than nonindigenous. ${ }^{12,13} \mathrm{Ed}$ ucational attainment, occupation and family background predominately explain the gap in poverty: Indigenous peo-

*Indigenous groups make up an estimated $50-66 \%$ of the total population of Bolivia (sources: Del Popolo F and Oyarce AM, Latin America, indigenous population: sociodemographic profile in the framework of the International Conference on Population and Development and the Millennium Goals, Notas de Población, 2005, No.79,pp.13-52 (in Spanish); and Instituto Nacional de Estadística (INE), Bolivia: percent distribution of the population 12 years and over by sex, area and ethnic self-identification, La Paz, Bolivia: INE, 2007 (in Spanish)). The variation in estimates across surveys is due to different measures used to identify indigenous ethnicity (e.g., geographical location, language and self-identification). According to the definition used in this article, $53 \%$ of the women in the DHS sample were indigenous. 
ple tend to come from more disadvantaged family backgrounds, have lower levels of education and work in lower paying occupations. However, the indigenous remain disadvantaged even when these compositional differences are taken into account, which suggests the possibility of employment-related discrimination. Although the national identity of Bolivia has moved toward a multicultural mix, discrimination toward the indigenous populations remains strongly embedded. ${ }^{14}$

Women, regardless of ethnicity, should be able to control the number and timing of their births. The inability to control fertility is an incursion upon basic human rights, and can lead to increased poverty and to poor child and maternal health outcomes. ${ }^{2}$ In a 1989 comparative study of eight Latin American countries, Bolivia had the highest proportion of pregnancies that were unwanted (44\%), reflected in a TFR of 5.0 and a desired fertility rate of $2.8 .^{3}$ According to another comparative study that included 13 Latin American countries, Bolivia had the highest proportion of unwanted births in 2003 (63\%)-a percentage unchanged from 1989, despite drops in the unwanted fertility rate. ${ }^{2}$ The findings suggest that the fertility preference in Bolivia is decreasing faster than the actual fertility rate. An estimated $49 \%$ of Bolivian women at the end of their reproductive years (aged 45-49) reported surpassing their ideal family size. ${ }^{4}$ And in one of the few studies investigating indigenous fertility (albeit without a comparison with nonindigenous fertility), in 1994, indigenous Bolivian women's ideal number of children was much lower than their actual TFR (2.4 vs. 6.5). ${ }^{15}$

Barriers to contraceptive knowledge, access and use can substantially increase unwanted fertility. ${ }^{3,5-7}$ An individual's desire not to use contraceptives can be considered a preference-related barrier, which may derive from conflicting desires and beliefs. For example, women may want to limit their fertility, but have a socially or culturally based preference not to practice contraception. In addition, indigenous women's fears about actual or perceived side effects of contraceptives, or of modern medicine in general, may dissuade them from using modern contraceptives and encourage them to use less effective traditional methods. ${ }^{16}$ Furthermore, the cultural segregation of indigenous people limits diffusion of positive attitudes toward contraception. ${ }^{17}$

In addition, such structural barriers as lack of economic resources or access to medical care-which in Bolivia can prevent indigenous populations from obtaining contraceptives-may deter contraceptive use despite desire to limit fertility. ${ }^{15,18,19}$ Supply-side factors may serve as structural barriers by making access to contraceptives too difficult. For example, the inclusion of family planning in the national agenda of Bolivia two decades ago has contributed to the shortage of subsidized contraceptives in remote areas, because the centers with subsidized contraceptives remain highly concentrated in urban areas, limiting the access of women living in remote areas to affordable contraceptives. ${ }^{20}$
Bolivia struggles to provide medical care for its multiethnic population. ${ }^{16}$ Multilingual services are not universally available, ${ }^{15,19}$ and discrimination deters indigenous women from visiting family planning clinics. A case study of family planning services in El Alto found that although medical providers were unaware of the problem, many patients reported discrimination toward the poor and those wearing traditional indigenous dress. ${ }^{21}$ Indigenous women often rely on husbands or other male relatives to act as their representative when interacting with authority figures; in situations such as discussing family planning with a medical provider, indigenous women may find it difficult to communicate openly, because they are not used to openly sharing personal information with authority figures. ${ }^{22}$ Moreover, medical providers tend to use formal medical language that indigenous women may not understand, which can further prevent indigenous women from feeling comfortable communicating with their medical providers.

In Bolivia, indigenous men are typically more educated and more likely to be bilingual than indigenous women, ${ }^{15}$ and even though their involvement in reproductive health is low, men are more likely to be informed about contraception and are more accustomed to interacting with institutions such as medical centers to obtain contraceptives. However, men do not always share their partner's fertility preferences or attitudes toward contraception. ${ }^{23-25}$ Men may discourage contraceptive use for a variety of reasons, such as a desire for more children, fear of female sexual infidelity or perceived interference with sexual pleasure. And even if men approve of family planning, they may not feel comfortable visiting a family planning clinic or may resist family planning information relayed by their female partners, because of social and cultural gender norms. ${ }^{22}$ Couples may have a preference to limit fertility, but their social and cultural context may make it difficult for men, and consequently for women, to use family planning clinics. Male preferences are important, but are overlooked in both unwanted fertility and unmet need measures. The male partner's role in mediating interactions with medical facilities could increase his power in decision making, hindering women's access to services. Male preferences could be linked to unwanted fertility, if they discourage women's contraceptive use.

\section{METHODS}

\section{Data and Sample}

The Bolivian Demographic and Health Survey (DHS) is a nationally representative household survey that includes a respondent questionnaire for women aged 15-49 and another questionnaire for a subset of their male partners. For this analysis, data from the 2003 DHS were used, because it is the most recent survey and the only one to report ethnicity. The 2003 data set included 17,654 female respondents, as well as a couple subsample of 2,873 women whose partners were also interviewed. ${ }^{25}$ Respondents who identified as "Quechua," "Aymara" or "Guaraní" 
were considered indigenous; nonindigenous people were those who responded "None" for ethnicity. Respondents with missing or "other" ethnicity were excluded, reducing the female sample size to 17,393 *

For the couple analysis, the sample was limited to ethnically endogamous couples, to focus on gender dynamics within ethnicity. The dynamics of exogenous couples likely differ from those of endogamous couples, which would complicate the comparison of indigenous and nonindigenous couple dynamics. Furthermore, the analysis of couples was limited to those in which women had a need for contraception; we excluded those who wanted to become pregnant within the next two years, those who were infecund and those who currently had a wanted pregnancy. The final couple sample consisted of 1,157 indigenous couples and 704 nonindigenous couples.

\section{Measures}

Three measures of women's fertility preferences were used: wanted total fertility, unmet need for contraception and contraceptive use. Contraceptive use also captures the influences of men's preferences and couple barriers.

Estimating the proportions of total fertility attributable to wanted and unwanted fertility can provide insight into why the TFR for indigenous women is greater than that for nonindigenous women. The total wanted fertility rate was calculated using a method developed by Bongaarts, ${ }^{\dagger 26}$ by adding an additional child to the TFR of women who reported wanting more children-those who responded "have another" and "undecided" to the fertility preference item on the DHS. ${ }^{\ddagger}$ A small correction was subtracted to ac-

\footnotetext{
*The DHS report does not mention ethnicity in the technical report; therefore, any type of sampling error on ethnicity alone is unknown. All analyses are weighted, however, to account for sampling errors.

†Total wanted fertility was estimated from actual fertility data on recent births and future preferences. The results avoid a posteriori rationalization, but a main disadvantage of the measure is the inability to account for changing preferences (sources: references 2 and 4). The measure may not be able to perfectly predict wanted fertility; however, a substantial ethnic difference in wanted total fertility is telling.

‡The measure of wanting more children is different for pregnant women than for other women because it is unclear if pregnant women include their current pregnancy when answering whether they want more children. For pregnant women, the measure is defined by comparing a woman's total number of live children to her ideal family size. If her current pregnancy surpasses her ideal family size, then she is coded as not wanting another child. Conversely, women whose pregnancy falls within her ideal family size are coded as wanting another child (source: reference 26).

$\S$ Bongaarts includes two additional errors for time trend and duration of reference period. The error for time trend was not accounted for here because it requires annual rates that cannot be calculated with DHS data. As the two errors are small in most incidences and offset each other, their exclusion should not invalidate this study's results (source: reference 26).

**The concepts of wanted and unwanted fertility are defined differently for "want more" fertility rates and unmet need. Want more fertility measures the lifetime fertility of an average woman, assuming fertility and fertility desires remain constant. A mistimed birth is not considered unwanted, because it could fit into a wanted lifetime fertility preference. Unmet need, however, is addressing current fertility desires, and thus incorporates mistimed births as unwanted. Thus, in this study, pregnant women were considered to have an unmet need if they did not want their current pregnancy at the time of conception, but had not been using a contraceptive method when they became pregnant, because excluding these women would underestimate unmet need (sources: references 5 and 6).
}

count for women in a union who wanted more children but were at the end of their reproductive years (aged 40-49) and those who said they did not want any children

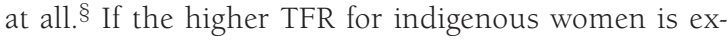
plained by wanted births, we can conclude that indigenous women want larger families. If, however, the higher TFR results from unwanted births, it may reflect structural barriers or men's preferences.

The social marginalization of the indigenous populations may make practicing contraception to limit fertility more difficult for them than for the nonindigenous population. To examine preferences and actualization through behavior, unmet contraceptive need was estimated for each population. The measure was derived from a constructed DHS variable that used several variables to define fecund females in a union who are not using a contraceptive method and do not want a birth within the next two years. The measure was recast into a dummy variable coding both "unmet need to space" and "unmet need to limit" as $1=y e s$. A high unmet need would suggest unwanted fertility driven by something other than women's preferences.

The wanted fertility and unmet need measures overlook the couple dynamics involved in fertility decisions. Measuring the contraceptive use of women who currently want no more children provides an opportunity to test for men's preferences or couple dynamics as barriers to contraceptive use, which might vary by ethnicity.** A dichotomous dummy variable "uses a modern method" was created from the response to a question regarding current contraceptive use, for which "modern method" was coded as 1 and "no method," "folk method" and "traditional method" were each coded as 0 . Another dichotomous dummy variable, "uses any method," was created by coding "modern method," "folk method" and "traditional method" as 1, and "no method" as 0 .

Selected background characteristics potentially related to contraceptive use were included to control for compositional differences between the indigenous and nonindigenous populations. Women were divided into four age-groups: 15-24, 25-34, 35-44 and 45-49 (for men, the last category was 45-64). Adjusted parity was defined as a woman's number of live births (including any current pregnancy). Educational attainment level was measured separately for men and women as none, incomplete primary, complete primary, incomplete secondary, complete secondary and more than complete secondary.

Several variables that measure women's, men's and couples' attitudes toward family planning and fertility were included. A measure of women's attitude toward family planning was dichotomized into "approves" or "disapproves/ doesn't know." For couples, the attitude toward family planning was divided into four categories: "both approve," "man approves," "woman approves" and "both disapprove/don't know." To look at men's preferences and couple discordance about fertility, a variable measuring whether the male partner reported wanting another child was included. Men who responded "wants within two 
years," "wants but unsure of timing" or "undecided" were considered to want another child, and those who responded "wants after two or more years" and "wants no more" were considered to not want another child; those who reported having been "declared infecund" and those with missing data were excluded.

Another set of variables was included to provide insight on social and cultural couple dynamics on communication and how women take their perception of their partner's preferences into account regarding contraceptive use. Communication about family planning has been linked to increased couple agreement with family planning approval and has shown a positive association with contraceptive use. ${ }^{27-30}$ Moreover, in a study in Kenya, a woman's perception of her partner's approval strongly predicted contraceptive use, even though her perception was not always accurate. ${ }^{29}$ Among indigenous couples, communication about family planning can be hindered by the negative social attitude toward discussing sexual matters openly, especially between the sexes. ${ }^{16,31}$ Indigenous couples, therefore, may have more difficulty in actualizing fertility preferences.

A variable of the woman's perception of whether the couple had discussed family planning was coded 1 for "once or twice" or "more often," and 0 for "never." Another variable measured whether the woman thought her partner approved or disapproved of family planning; the response option "don't know" was available for women who were unsure of their partner's feelings toward family planning. A similarly framed question asked each woman her perception of her partner's fertility desire in relation to her own; possible responses were "both want same," "man wants more," "man wants fewer" and "don't know."

\section{Analysis}

Wanted TFR and unmet contraceptive need were calculated by ethnicity. Kappa statistics, which measure agreement, were calculated separately by ethnicity, to compare women's perception of their partner's family planning approval with his own report. Kappa statistics were also used to gauge the prevalence of spousal discordance for each ethnic group and examine the degree of conflicting ideologies within the couple that could create barriers to both partners actualizing their fertility preferences.

An initial chi-square analysis was conducted to identify any differences $(p<.05)$ between indigenous and nonindigenous women in their practice of family planning, both overall and in reliance on traditional versus modern contraceptive methods, which are more effective in preventing pregnancy. ${ }^{32}$ Then two sets of five logistic regression models were created to examine associations between women's, men's and couples' preferences and ethnic differences in women's use of any contraceptive method and use of a modern method. The baseline model includes ethnicity only. The second model adds the woman's background and socioeconomic variables (age, parity and education) to account for compositional differences. The third model adds the woman's attitudinal variable (family
TABLE 1. Percentage distribution of women in ethnically endogamous couples in need of contraception, by ethnicity, according to selected characteristics, Bolivian Demographic and Health Survey, 2003

Characteristic

Indigenous Nonindigenous $(\mathrm{N}=1,157) \quad(\mathrm{N}=704)$

Outcome

Using modern contraceptive

$\begin{array}{lll}\text { Yes } & 27.3 & 61.2\end{array}$

$\begin{array}{lll}\text { No } & 72.7 & 38.8\end{array}$

Using any contraceptive

Yes

56.3

No

Background

Woman's age $\begin{array}{lll}15-24 & 16.9 & 23.4\end{array}$

25-34

$35-44$

$45-49$

36.3

35.7

11.2

Man's age

$15-24$

25-34

$35-44$

$45-64$

Parity†

0

1

2

3

4

5
$\geq 6$

$\geq 6$

Woman's education

None

Incomplete primary

Complete primary

Incomplete secondary

Complete secondary

$>$ complete secondary

Man's education

None

Incomplete primary

Complete primary

Incomplete secondary

Complete secondary

>incomplete secondary

$\begin{array}{rr}8.4 & 8.1 \\ 35.5 & 37.1\end{array}$

Attitudinal

Woman's approval of family planning Approves 83.6

Disapproves/don't know $\quad 16.4$

Couple's approval of family planning

Both approve

Man only approves

Woman only approves

Both disapprove/don't know

Man's desire for another child

No

Woman's perception

Couple's desire for children

$\begin{array}{lll}\text { Both want same } & 61.0 & 55.0\end{array}$

Man wants more $\quad 17.1 \quad 22.8$

$\begin{array}{lrr}\text { Man wants fewer } & 11.2 & 9.5 \\ & 10.7 & 12.8\end{array}$

$\begin{array}{lll}\text { Don't know } & 10.7 & 12.8\end{array}$

Partner's approval of family planning

Approves 76.6

Disapproves $\quad 10.3$

Don't know 13.1

Spousal discussion of family planning

Yes

82.0

No

18.0

87.2

6.3

6.5

89.5

10.5

Total

100.0

100.0

tFor pregnant women, includes living children and current pregnancy. 
planning approval.) The fourth model omits the woman's approval of family planning and includes the male- and couple-relevant variables (men's age, men's education, men's desire for another child and couple family planning approval) to determine the role of men's preferences and couple dynamics in contraceptive use. Finally, the fifth model excludes the male- and couple-relevant variables and includes woman's approval of family planning and the three perception variables (woman's perception of whether the couple had discussed family planning, woman's perception of her partner's family planning approval and woman's perception of whether the spouses' fertility desires agree) to further look at couple dynamics.

\section{RESULTS}

\section{Couple Sample Characteristics}

In the couple sample, the proportion of women practicing contraception differed by ethnicity (Table 1, page 169). A smaller proportion of indigenous women than of nonindigenous women reported using a modern contraceptive method ( $27 \%$ vs. $61 \%$ ) or any method ( $56 \%$ vs. $74 \%$ ). The two ethnic groups also differed in background and socioeconomic characteristics. Compared with nonindigenous women and men from the couple sample, indigenous women and men were slightly older, had higher parity and were less educated. Furthermore, within ethnic groups, women tended to be younger than men and had lower educational attainment.

The majority of women and couples in both ethnic groups approved of family planning; however, smaller proportions of indigenous women and couples than of their nonindigenous counterparts approved. Approval was 11 percentage points lower for indigenous women than for nonindigenous women ( $84 \%$ vs. 95\%) and 23 percentage points lower for both partners of indigenous couples than for both partners of nonindigenous couples (64\% vs. $87 \%$ ). Indigenous couples had more discordance in their attitudes toward family planning: In $10 \%$ of indigenous couples, the male partner approved of family planning but the female partner did not, and in 20\%, the female partner approved but not the male; the proportions among non-

\begin{tabular}{|c|c|c|c|c|}
\hline \multirow[t]{2}{*}{ Parity } & \multicolumn{2}{|l|}{$\begin{array}{l}\text { Indigenous } \\
(\mathrm{N}=5,816)\end{array}$} & \multicolumn{2}{|c|}{$\begin{array}{l}\text { Nonindigenous } \\
(\mathrm{N}=4,633)\end{array}$} \\
\hline & $\begin{array}{l}\text { Want } \\
\text { another child }\end{array}$ & $\begin{array}{l}\text { Unmet } \\
\text { need }\end{array}$ & $\begin{array}{l}\text { Want } \\
\text { another child }\end{array}$ & $\begin{array}{l}\text { Unmet } \\
\text { need }\end{array}$ \\
\hline All & 25.2 & 25.7 & 33.9 & 18.8 \\
\hline 0 & 78.7 & 8.9 & 89.9 & 13.0 \\
\hline 1 & 65.3 & 21.0 & 69.7 & 18.3 \\
\hline 2 & 26.9 & 19.4 & 36.3 & 15.9 \\
\hline 3 & 14.5 & 26.8 & 22.6 & 17.2 \\
\hline 4 & 9.2 & 24.2 & 14.2 & 20.7 \\
\hline 5 & 11.8 & 31.4 & 12.2 & 27.9 \\
\hline$\geq 6$ & 9.8 & 33.4 & 10.1 & 23.3 \\
\hline
\end{tabular}

indigenous couples were $4 \%$ and $8 \%$, respectively. In a greater proportion of indigenous couples than of nonindigenous couples, both partners disapproved of family planning or reported that they did not know (7\% vs. 1\%). A small minority of men in each ethnic group wanted another child; however, the proportion of indigenous men who did so was less than half that of nonindigenous men ( $5 \%$ vs. $12 \%$ ).

Compared with nonindigenous women, a greater proportion of indigenous women perceived that they and their partner wanted the same number of children $(61 \%$ vs. $55 \%$ ) or that their partner wanted fewer children ( $11 \%$ vs. 10\%). Eleven percent of indigenous women and 13\% of nonindigenous women said they did not know their partner's desire for children relative to their own. More than three-quarters of women of both ethnicities perceived that their partner approved of family planning; however, greater proportions of indigenous women than of nonindigenous women believed that their partner disapproved ( $10 \%$ vs. $6 \%$ ) or said they did not know his attitude (13\% vs. $7 \%$ ). Last, $82 \%$ of indigenous women and $90 \%$ of nonindigenous women reported ever talking with their partner about family planning.

\section{Wanted Fertility}

According to the 2003 Bolivian DHS, the estimated TFR for all respondents was 3.8. ${ }^{33}$ The TFRs for indigenous and nonindigenous women were calculated to be 4.3 and 3.1, respectively. Surprisingly, the wanted fertility rate was nearly identical for the two groups ( 1.5 for indigenous women and 1.7 for nonindigenous women), so the rate of unwanted fertility was greater for indigenous women than for nonindigenous women (2.8 vs. 1.4). This indicates that the difference in TFR between ethnic populations can be attributed almost entirely to indigenous women's higher unwanted fertility.

Among all female DHS respondents who reported being in a union, $25 \%$ of indigenous women and 34\% of nonindigenous women reported wanting another child (Table 2). In fact, in every level of adjusted parity except parity 1 and parity $\geq 6$, a significantly greater proportion of nonindigenous women than of indigenous women reported wanting another child.

Twenty-six percent of indigenous women and 19\% of nonindigenous women had an unmet need for contraception. At every level of adjusted parity except zero, a greater proportion of indigenous women than of nonindigenous women did not want another child within the next two years but were not practicing contraception. Interestingly, the second-highest ethnic difference in unmet need (10 percentage points) was found at parity 3 , with $27 \%$ of indigenous women and $17 \%$ of nonindigenous women having unmet need. This finding suggests that at the point when most women have reached their preferred level of fertility, indigenous women are less likely than nonindigenous women to use a contraceptive method.

The kappa scores revealed that indigenous couples 
agreed more often than nonindigenous couples about wanting another child ( $90 \%$ and $82 \%$, respectively). However, when female partners did not want a child, indigenous women were more likely than nonindigenous women to incorrectly perceive their partner's approval of family planning (kappa statistics, 66\% and 82\%, respectively).

\section{Multivariate Analyses}

Women's fertility preferences do not explain ethnic differences in fertility. In the next step, multivariate models examine whether couple barriers or men's preferences play a part in women's contraceptive use, and whether such variables are systematically linked to differences in ethnicity.

-Any contraceptive use. In the first logistic regression model in Table 3, which includes no controls, indigenous women's odds of using any contraceptive method were lower than those of nonindigenous women (odds ratio, 0.43). After the addition of women's age, parity and education to the model, the gap between indigenous and nonindigenous women in the odds of contraceptive use closed slightly (0.50). Women aged 25-34 and 35-44 were more likely than those aged $15-24$ to use a contraceptive method (2.9 and 4.0, respectively), and women who had a complete primary education and those with more schooling were more likely to practice contraception than women who had not completed primary school (3.4 and 5.0 , respectively). Compared with women who had had 0-2 children, those who had had 3-5 and six or more children had lower odds of contraceptive use (0.7 and 0.4, respectively).

In the third model, which added women's approval of family planning, indigenous women's relative odds of using a contraceptive method rose slightly (odds ratio, 0.54), suggesting that women's attitudes account for some of the ethnic difference in contraceptive use. Not surprisingly, women's disapproval of family planning was negatively associated with contraceptive use (0.2). The associations with women's age, parity and education remained significant.

In the next model, which added men's and couples' variables but omitted women's approval of family planning, the odds of indigenous women using any contraceptive again increased slightly (odds ratio, 0.61). Women's age, parity and women's education remained associated with contraceptive use. Of the men's and couples' variables, however, only couples' approval of family planning was significant: Compared with couples in which both spouses approved of family planning, all other couple combinations were less likely to use contraceptives (0.1-0.5). The odds of contraceptive use were lower for couples in which only the man approved than for couples in which only the woman approved. Not surprisingly, the odds of use were lowest for couples in which both spouses disapproved.

In the final model, social and cultural couple dynamics were examined through women's perception of their partner's preferences, which resulted in a further attenuation
TABLE 3. Odds ratios from logistic regression analyses assessing the association between selected characteristics and women's use of any contraceptive method

Characteristic Model 1 Model 2 Model 3 Model 4 Model 5

\section{Ethnicity}

$\begin{array}{llllll}\text { Nonindigenous (ref) } & 1.00 & 1.00 & 1.00 & 1.00 & 1.00\end{array}$

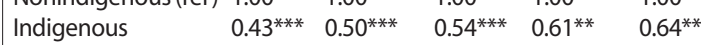

Background

Woman's age

15-24 (ref)

25-34

35-44

45-49

Man's age

15-24 (ref)

25-34

35-44

45-64

Parity

0-2 (ref)

$3-5$

$\geq 6$

Woman's education

$<$ primary (ref)

Primary

$>$ primary

Man's education

$<$ primary (ref)

Primary

$>$ primary

$\begin{array}{lllll}\text { na } & 1.00 & 1.00 & 1.00 & 1.00 \\ \text { na } & 2.85^{* * *} & 2.83^{* * *} & 2.82^{* * *} & 2.75^{* * *} \\ \text { na } & 4.00^{* * *} & 4.63^{* * *} & 4.32^{* * *} & 4.48^{* * *}\end{array}$

na $4.00^{* * *}-4.63^{* * *} \quad 4.32^{* * *}-4.48^{* * * *}$

$\begin{array}{lllll}\text { na } & 1.72 & 1.78 & 1.37 & 1.47\end{array}$

na na na $1.00 \quad$ na

na na na 0.90 na

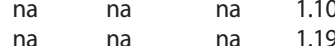

$\begin{array}{lllll}\text { na } & 1.00 & 1.00 & 1.00 & 1.00 \\ \text { na } & 0.66^{*} & 0.64^{*} & 0.66^{*} & 0.66^{*}\end{array}$

$\begin{array}{llll}0.66^{*}-0.64^{*}-0.66^{*}-0.66^{*} & 0.46\end{array}$

na $\quad 0.39^{* * *} \quad 0.37^{* * *} \quad 0.37^{* * *} \quad 0.46^{* *}$

$\begin{array}{lllll}\text { na } & 1.00 & 1.00 & 1.00 & 1.00\end{array}$

na $3.36^{* * *} \quad 2.68^{* * *} \quad 2.51^{* * *} \quad 2.90^{* * *}$

na $5.01^{* * *} \quad 3.54^{* * *} \quad 2.52^{* *} \quad 3.00^{* * *}$

na na na 1.00 na

na na na 1.30 na

Attitudinal

Woman's approval of family planning

\begin{tabular}{|c|c|c|c|c|c|}
\hline Approves (ref) & na & na & 1.00 & na & 1.00 \\
\hline $\begin{array}{l}\text { Disapproves/ } \\
\text { don't know }\end{array}$ & na & na & $0.16^{* * *}$ & na & $0.47^{* *}$ \\
\hline \multicolumn{6}{|c|}{ Couple's approval of family planning } \\
\hline Both approve (ref) & na & na & na & 1.00 & na \\
\hline Man only & na & na & na & $0.18^{* * *}$ & na \\
\hline Woman only & na & na & na & $0.53^{* * *}$ & na \\
\hline $\begin{array}{l}\text { Both disapprove/ } \\
\text { don't know } \\
\text { Man's desire for anot }\end{array}$ & $\begin{array}{l}\text { na } \\
\text { r ch }\end{array}$ & na & na & $0.06^{* * * *}$ & na \\
\hline No (ref) & na & na & na & 1.00 & na \\
\hline Yes & na & na & na & 1.02 & na \\
\hline
\end{tabular}

Yes

na

Woman's perception

Couple's desire for children

Both want same

(ref)

Man wants more

Man wants fewer

Don't know

na

na na $\quad 1.00$

Approves (ref)

Disapproves/

don't know

na na

na na

Spousal discussion of family planning

No (ref)

na

na

Yes

na na

${ }^{*} \mathrm{p}<.05{ }^{* *} \mathrm{p}<.01 . * * * \mathrm{p}<.001$. Notes: na=not applicable. For multivariate analysis, the education categories in Table 1 were condensed: "none" and "incomplete primary" became "<primary"; "complete primary" became "primary"; and "incomplete secondary," "complete secondary" and ">complete secondary" became "> primary."

of the gap between indigenous women's and nonindigenous women's odds of using contraceptives (odds ratio, 0.64). The relationships between contraceptive use and women's age, parity, women's education and women's approval of family planning remained similar to those in previous models. Women's odds of contraceptive use were 
TABLE 4. Odds ratios from logistic regression analyses assessing the association between selected characteristics and women's use of a modern contraceptive method

Characteristic Model 1 Model 2 Model 3 Model 4 Model 5

Ethnicity

$\begin{array}{llllll}\text { Nonindigenous (ref) } & 1.00 & 1.00 & 1.00 & 1.00 & 1.00\end{array}$

$\begin{array}{llllll}\text { Indigenous } & 0.19^{* * *} & 0.22^{* * *} & 0.23^{* * *} & 0.25^{* * *} & 0.27^{* * *}\end{array}$

Background

Woman's age

15-24 (ref)

25-34

$35-44$

45-49

Man's age

15-24 (ref)

25-34

35-44

45-64

Parity

$0-2$ (ref)

3-5

$\geq 6$

Woman's education

$<$ primary (ref)

Primary

$>$ primary

Man's education

$<$ primary (ref)

Primary

>primary

$\begin{array}{lllll}\text { na } & 1.00 & 1.00 & 1.00 & 1.00 \\ \text { na } & 1.25 & 1.21 & 1.24 & 1.09 \\ \text { na } & 1.39 & 1.43 & 1.32 & 1.03\end{array}$

Attitudinal

Woman's approval of family planning

$\begin{array}{lllll}\text { Approves (ref) na na } & 1.00 & \text { na } & 1.00\end{array}$

Disapproves/

don't know na na

Couple's approval of family planning

Both approve (ref) na na

Manonly na na

Woman only

na

Both disapprove/

don't know

na na

Man's desire for another child

No (ref)

Yes

na na

na na

$0.16^{* * *}$ na

$0.16^{* * *}$

Woman's perception

Couple's desire for children

Both want same (ref) na

Man wants more na

Man wants fewer na

Don't know na na
Partner's approval of family planning

Approves (ref)

Disapproves/

na na

1.00 na

na $0.16^{* * *}$ na

na $0.46^{* * *}$ na

na $0.03^{* *}$ na

don't know na na

Spousal discussion of family planning

No (ref)

na na

na na

na

$\begin{array}{ccc}\text { na } & \text { na } & 1.00 \\ \text { na } & \text { na } & 1.44 \\ \text { na } & \text { na } & 0.96 \\ \text { na } & \text { na } & 0.59^{*} \\ & & \\ \text { na } & \text { na } & 1.00 \\ & & \\ \text { na } & \text { na } & 0.43^{* *} \\ & & \\ \text { na } & \text { na } & 1.00 \\ \text { na } & \text { na } & 1.27\end{array}$

${ }^{*} \mathrm{p}<.05 .{ }^{* *} \mathrm{p}<.01 .{ }^{* * *} \mathrm{p}<.001$. Notes: na $=$ not applicable. For multivariate analysis, the education categories in Table 1 were condensed: "none" and "incomplete primary" became "<primary"; "complete primary" became "primary"; and "incomplete secondary," "complete secondary" and ">complete secondary" became "> primary."

not associated with whether they thought their partner wanted more or fewer children than they did; however, compared with women who thought that they and their partner wanted the same number of children, those who did not know their partner's fertility desires had lower odds of contraceptive use (0.6). Women who thought their partner disapproved of family planning or did not know their partner's attitude had odds of contraceptive use sharply lower than women who thought their partner approved of family planning (0.1). Of the models with controls, this final model explained the ethnic differentials most successfully, with a 21 percentage-point reduction in the difference in the odds of contraceptive use by ethnicity, compared with the initial model.

- Modern contraceptive use. In the first model in Table 4, indigenous women's odds of using a modern contraceptive method were significantly lower than those of nonindigenous women (odds ratio, 0.19). After adding women's age, parity and education, the ethnic difference in the likelihood of modern contraceptive use decreased modestly (0.22). Of the added variables, however, only women's education was significant: Women who had a complete primary education and those with more than primary schooling were more likely than women who did not complete primary school to use a modern contraceptive (1.7 and 2.8, respectively).

In the third model, which included women's approval of family planning, the addition decreased the ethnic difference in modern contraceptive use in the previous model slightly (odds ratio, 0.23 ). Women who disapproved of family planning or did not know their attitude were less likely than others to use a modern method (0.2). Having more than a primary education remained positively associated with modern contraceptive use (2.1), but having only a primary education lost significance.

The fourth model added men's and couples' variables, but omitted women's approval of family planning. Indigenous women still exhibited significantly lower odds of using modern contraceptives compared with nonindigenous women (odds ratio, 0.25). Furthermore, the malespecific variables (age, education and desire for another child) were not significant, suggesting that men do not have a strong influence on women's use of modern contraceptives. Compared with couples in which both partners approved of family planning, couples in which neither spouse approved had 97\% lower odds of using modern contraceptives; couples in which only the man approved or only the woman approved also had reduced odds of modern contraceptive use ( 0.2 and 0.5 , respectively). For women, having more than a primary education remained positively associated with modern contraceptive use (2.1), but being aged 45-49 became negatively associated with use of a modern method (0.4).

In the last model, measures of the male partner's characteristics and attitudes were replaced with those of the woman's perception of her partner's attitudes to examine the social and cultural aspects of couple dynamics. Once again, the ethnic difference in the likelihood of using a modern method decreased slightly (odds ratio, 0.27 ). The gap between indigenous and nonindigenous women's likelihood of using modern contraceptives is best explained by the model including women's perception of their partner's approval of family planning and his fertility desires. However, this model accounts for only an eight 
percentage-point reduction in the difference in the odds of modern contraceptive use by ethnicity, compared with the initial model, suggesting that the decision to use modern methods is likely influenced by various structural barriers, such as affordability and access.

\section{DISCUSSION}

According to the findings of this study, the difference in total fertility rates between indigenous and nonindigenous populations in Bolivia results almost entirely from higher unwanted fertility-not a desire for larger families-among indigenous women. Many factors may contribute to this difference in unwanted fertility. In the current study, approval of family planning was lower among indigenous women and couples, and indigenous women were less accurate at predicting their partner's family planning approval. In addition, indigenous women were less likely to have discussed family planning with their partners, which could have dissuaded them from using contraceptives if they felt that their partner's approval was needed. Therefore, cultural barriers that inhibit indigenous couples from discussing family planning could contribute to unmet need and unwanted fertility.

Men may not always agree with their partners in regard to the wantedness of a pregnancy or birth and can affect unmet need by discouraging contraceptive use. Indigenous couples, however, had higher agreement than nonindigenous couples in regard to their fertility desires, with most agreeing on not wanting another child. Moreover, a smaller proportion of indigenous men than of nonindigenous men wanted another child. This suggests that the higher level of unwanted fertility among the indigenous was not caused by couple discordance or men's higher fertility preferences.

Indigenous women had a higher unmet need for contraception than nonindigenous women. A possible explanation is that approval of family planning is more important than fertility preferences in predicting use of contraceptives. Women's perception of their partner's family planning approval was associated with their likelihood of using contraceptives, yet one-third of indigenous women incorrectly predicted their partner's attitude. This suggests that couple dynamics that impede the quality of spousal communication and indigenous men's lower approval of family planning may contribute to indigenous unwanted fertility. However, neither actual approval nor women's perception of men's approval largely explains ethnic differences in contraceptive use-especially modern method use. Therefore, the barriers created by couple dynamics and men's preferences are modest at most.

Interestingly, the ethnic differences in the odds of using a modern contraceptive were larger than those in the odds of using any method; in addition, these differences were less affected by the control variables, which suggests a significant unknown predictor of modern method use. Furthermore, a woman's perception of her husband's family planning approval was significantly more important than the woman's own disapproval in predicting her odds of using any contraceptive method, although the opposite is true for her odds of using a modern method. The difference between all methods and modern methods is the inclusion of traditional methods, which suggests that women who use modern methods are more driven by their own attitude toward family planning, whereas women who use traditional methods are more likely to be influenced by what they believe their partner thinks.

\section{Policy Implications}

Unwanted fertility may exacerbate poverty and ethnic inequality prevalent throughout Bolivia. By addressing ethnic differences in unwanted fertility, family planning programs and policies aimed at reducing unwanted fertility could become more effective in addressing the particular needs of indigenous populations. This study's findings point to several important avenues for future research.

Women's preferences appear not to be the driving force behind higher fertility in indigenous populations; therefore, future studies and policy initiatives should focus on structural barriers to contraceptive use. Rather than focusing solely on women, family planning clinics should create a welcoming environment for men and encourage couples to communicate about reproductive matters. Family planning programs could reduce social and cultural barriers to contraceptive use by educating men about the advantages of family planning, particularly those in couples wary of modern methods

Indigenous populations' access to contraceptives should also be examined. Poverty and remote location of clinics may be obstructing indigenous women and men from obtaining contraceptives needed to reduce unwanted fertility. In addition, research is needed to determine whether culturally insensitive policies and behavior might be preventing indigenous couples from accessing contraceptives.

Furthermore, this study focused on endogamous couples. The vast majority of Bolivian women have children within an ethnically endogamous union, but that does not lessen the need of single women or women in exogenous unions to avoid unwanted pregnancy. Future studies should consider the implications of unwanted fertility for women of different union statuses and those in exogamous couples, to address all women's needs and the potential multiple combinations of gender and ethnicity.

\section{REFERENCES}

1. Gray GM, Ethnic politics in Bolivia, 1900-2000: 'harmony of inequalities' 1900-2000, working paper, Oxford, UK: Centre for Research on Inequality, Human Security and Ethnicity, 2007, No. 15.

2. Casterline JB and Mendoza JA, Unwanted fertility in Latin America: historical trends, recent patterns, paper presented at the annual meeting of the Population Association of America, Detroit, MI, USA, Apr. 30-May 2, 2009

3. Westoff $C$ and Lorenzo M, Reproductive intentions and fertility in Latin America, in: Guzman JM et al., eds., The Fertility Transition in Latin America, Oxford, UK: Oxford University Press/International Union for the Scientific Study of Population (IUSSP), 1996, pp. 242-251. 
4. Hakkert R, Levels and determinants of wanted and unwanted fertility in Latin America, paper presented at the general conference of the IUSSP, Salvador de Bahia, Brazil, Aug. 18-24, 2001

5. Westoff C, Unwanted fertility in six developing countries, International Family Planning Perspectives, 1981, 7(2):43-52.

6. Bongaarts J, Trends in unwanted childbearing in the developing world, Studies in Family Planning, 1997, 28(4):267-277.

7. Blanc AK, Unwanted fertility in Latin America and the Caribbean, International Family Planning Perspectives, 1982, 8(4):156-162.

8. Barrios RM, The Indigenous Towns of Bolivia: Sociodemographic Diagnosis from the 2001 Census, Santiago, Chile: Commission for Latin America and the Caribbean, 2005 (in Spanish).

9. Van Cott DL, Party system development and indigenous populations in Latin America: the Bolivian case, Party Politics, 2000, $6(2): 155-174$.

10. Arocena F, Multiculturalism in Brazil, Bolivia and Peru, Race $E$ Class, 2008, 49(1):1-21.

11. Patrinos HA, Skoufias E and Lunde T, Indigenous peoples in Latin America: economic opportunities and social networks, World Bank Policy Research Working Paper, Washington, DC: World Bank, 2007, No. 4227.

12. Psacharopoulos G, Ethnicity, education, and earnings in Bolivia and Guatemala, Comparative Education Review, 1993, 37(1):9-20

13. Hall G and Patrinos HA, Indigenous People, Poverty and Human Development in Latin America: 1994-2004, New York: Palgrave MacMillan, 2006.

14. Beneria-Surkin J, Has multiculturalism arrived? Reflections on indigenous people, power, development and knowledge in Bolivia, Planning Theory \& Practice, 2004, 5(1):109-118.

15. Terborgh A et al., Family planning among indigenous populations in Latin America, International Family Planning Perspectives, 1995, 21(4):143-149.

16. Schuler SR, Choque ME and Rance S, Misinformation, mistrust, and mistreatment: family planning among Bolivian market women, Studies in Family Planning, 1994, 21(4):211-221.

17. De Broe S and Hinde A, Diversity in fertility patterns in Guatemala, International Journal of Population Geography, 2006, 12(6):435-459.

18. Mantilla Castro MD and Antezana ML, Evaluation of Community Interventions in Sexual and Reproductive Health Services in UrbanMarginal Areas of La Paz, Bolivia, New York: Population Council, 2004, pp. 1-35.

19. Montenegro RA and Stephens C, Indigenous health in Latin America and the Caribbean, Lancet, 2006, 367(9525):1859-1869.

20. Policy project, Documentation of the Use of SPARHCS: Bolivia, <http://www.policyproject.com/pubs/policymatters/SPARHCSBolivia.Final.04.10.06.doc>, accessed Aug. 11, 2006

21. Velasco C et al., Quality of contraceptive services in El Alto, Bolivia, Pan American Journal of Public Health, 1999, 5(6):411-418 (in Spanish).

22. Paulson S and Bailey P, Culturally constructed relationships shape sexual and reproductive health in Bolivia, Culture, Health \& Sexuality, 2003, 5(6):483-498

23. Bankole A and Singh S, Couples' fertility and contraceptive decision-making in developing countries, International Family Planning Perspectives, 1998, 24(1):15-25.

24. Carter $M$ and Speizer IS, Pregnancy intentions among Salvadoran fathers: results from the 2003 National Male Reproductive Health Survey, International Family Planning Perspectives, 2005, 31(4): 179-182.

25. Casterline JB, Perez AE and Biddlecom AE, Factors underlying unmet need for family planning in the Philippines, Studies in Family Planning, 1997, 28(3):173-191.

26. Bongaarts J, The measurement of wanted fertility, Population and Development in Review, 1990, 16(3):487-506.

27. Bawah A, Spousal communication and family planning behavior in Navrongo: a longitudinal assessment, Studies in Family Planning, 2002, 33(2):185-194

28. DeRose LF et al., Does discussion of family planning improve knowledge of partner's attitude toward contraceptives? International Family Planning Perspectives, 2004, 30(2):87-93.

29. Lasee A and Becker S, Husband-wife communication about family planning and contraceptive use in Kenya, International Family Planning Perspectives, 1997, 23(1):15-22.

30. Sharan M and Valente TW, Spousal communication and family planning adoption: effects of a radio drama serial in Nepal, International Family Planning Perspectives, 2002, 28(1):16-25.

31. Bongaarts J and Bruce J, The causes of unmet need for contraception and the social content of services, Studies in Family Planning, 1995, 26(2):57-75.

32. Robey B, Ross J and Bhushan I, Meeting unmet need: new strategies, Population Reports, 1996, Series J, No. 43.

33. Sardan MG, Ochoa LH and Guerra WC, Bolivian Demographic and Health Survey Final Report, 2003, 2004, <http://www.measuredhs com/pubs/pdf/FR159/00FrontMatter.pdf>, accessed Oct. 28, 2006 (in Spanish).

\section{RESUMEN}

Contexto: En Bolivia, la tasa global de fecundidad (TGF) en poblaciones indígenas es más alta que la observada en la población no indígena. Es importante investigar si esta diferencia se puede atribuir a diferencias étnicas en la fecundidad deseada o no deseada.

Métodos: Se utilizaron los datos de la Encuesta de Demografía y Salud de Bolivia de 2003 para estimar las tasas globales de fecundidad deseada y no deseada en mujeres. Se condujo una serie de análisis de regresión logística para examinar si las características de las mujeres, hombres y parejas estaban asociadas con el uso de algún método anticonceptivo y de métodos modernos.

Resultados: Las TGF para mujeres indígenas y no indígenas fueron de 4.3 y 3.1, respectivamente. La tasa de fecundidad deseada para mujeres indigenas fue casi la misma que para las mujeres no indigenas (1.5 y 1.7 , respectivamente); virtualmente, toda la diferencia étnica en las TGF se atribuyó a las diferencias étnicas en la fecundidad no deseada. La proporción de mujeres que necesitan anticoncepción fue mayor entre las mujeres indígenas que entre las mujeres no indígenas (26\% vs 19\%). En análisis de regresión logística, las preferencias de fecundidad masculina explicaron solamente una pequeña parte de la diferencia étnica en el uso de anticonceptivos.

Conclusión: Las preferencias de las mujeres, hombres y parejas contribuyen solamente de manera marginal a la fecundidad no deseada, lo que sugiere que algunos factores estructurales actúan como obstáculos en la prevención de la fecundidad no deseada.

\section{RÉSUMÉ}

Contexte: En Bolivie, l'indice synthétique de fécondité parmi les populations indigènes est supérieur à celui relevé parmi la population non indigène. Il importe d'examiner si l'écart s'explique par une différence ethnique de fécondité désirée ou non.

Méthodes: Les indices de fécondité désirée ou non des femmes ont été estimés en fonction des données de l'Enquête démographique et de santé menée en Bolivie en 2003. L'analyse de ré- 
gression logistique a permis d'examiner l'association ou non des caractéristiques propres aux femmes, aux hommes et aux couples avec l'usage d'une méthode contraceptive quelconque et celui des méthodes modernes.

Résultats: Les indices synthétiques de fécondité se sont révélés de 4,3 et 3,1, respectivement, pour les femmes indigènes et non indigènes. La fécondité désirée des femmes indigènes s'est avérée proche de celle de leurs homologues non indigènes (1,5 et 1,7, respectivement); la totalité, pratiquement, de la différence ethnique est attribuable à la différence ethnique de fécondité non désirée. La proportion des femmes présentant un besoin de contraception est supérieure parmi les femmes indigènes (26\% vs 19\%). Comme le révèlent les analyses de régression, les préférences de fécondité masculines n'expliquent qu'une faible portion de la différence ethnique de pratique contraceptive.

Conclusion: Les préférences des femmes, des hommes et des couples ne contribuent que marginalement à la fécondité non désirée, laissant entendre que des facteurs structurels font obstacle à la prévention de la fécondité non désirée.

\section{Acknowledgments}

The author thanks Cynthia Buckley, Bob Hummer, Sarah McKinnon, Stephen McNamee, Joe Potter and Tom Pullum for providing invaluable feedback on this article, and John Casterline for his help in correcting the wanted and unwanted fertility rates for indigenous and nonindigenous women.

Author contact:catem@prc.utexas.edu 